\title{
How Accurate are Value-at-Risk Models at Commercial Banks?
}

Jeremy Berkowitz*

Graduate School of Management

University of California, Irvine
James O'Brien

Division of Research and Statistics

Federal Reserve Board

July 2001

\begin{abstract}
In recent years, the trading accounts at large commercial banks have grown substantially and become progressively more diverse and complex. We provide descriptive statistics on the trading revenues from such activities and on the associated Value-at-Risk forecasts internally estimated by banks. For a sample of large bank holding companies, we evaluate the performance of banks' trading risk models by examining the statistical accuracy of the VaR forecasts. Although a substantial literature has examined the statistical and economic meaning of Value-atRisk models, this article is the first to provide a detailed analysis of the performance of models actually in use.
\end{abstract}

Keywords: market risk, portfolio models, value-at-risk, volatility

Correspondence: Berkowitz: (949) 824-8472, e-mail: jberkowitz@gsm.uci.edu; O’Brien: (202) 452-2384, e-mail: jmobrien@frb.gov. We gratefully acknowledge the support and comments of Jim Embersit and Denise Dittrich of the Federal Reserve Board's Division of Supervision and Regulation, Philippe Jorion, Matt Pritsker, Mike Gibson, Hao Zhou, colleagues at the Federal Reserve Board and the New York Fed. The comments and suggestions of an anonymous referee were especially helpful in improving the paper. The opinions expressed do not necessarily represent those of the Federal Reserve Board or its staff. 
In recent years, the trading accounts at large commercial banks have grown rapidly and become progressively more complex. To a large extent, this reflects the sharp growth in the over-the-counter derivatives markets, in which commercial bank are the principal dealers. In order to manage market risks, major trading institutions have developed large scale risk measurement models. While approaches may differ, all such models measure and aggregate market risks in current positions at a highly detailed level. The models employ a standard risk metric, Value-at-Risk ( $\mathrm{VaR})$, which is a lower tail percentile for the distribution of profit and loss $(\mathrm{P} \& \mathrm{~L})$. VaR models have been sanctioned for determining market risk capital requirements for large banks by U.S. and international banking authorities through the 1996 Market Risk Amendment to the Basle Accord. Spurred by these developments, VaR has become a standard measure of financial market risk that is increasingly used by other financial and even nonfinancial firms as well.

The general acceptance and use of large scale VaR models has spawned a substantial literature including statistical descriptions of $\mathrm{VaR}$ and examinations of different modeling issues and approaches (for a survey and analysis see Jorion (2001)). Yet, because of their proprietary nature, there has been little empirical study of risk models actually in use, their VaR output, or indeed the P\&L distributions of trading firms. For the most part, VaR analyses in the public domain have been limited to comparing modeling approaches and implementation procedures using illustrative portfolios (e.g., Beder (1995), Hendricks (1996), Marshall and Siegel (1997), Pritsker (1997)). ${ }^{1}$

In this paper, we provide the first direct evidence on the performance of bank VaR models. We analyze the distribution of historical trading P\&L and the daily performance of VaR estimates of 6 large U.S. banks. All are large multinational institutions and meet the Basle "large trader" criterion-with trading activity equal to at least at 10 percent of total assets or $\$ 1$ billion. The banks include the largest US bank derivative dealers and all are in the top 10 in terms of notional amounts outstanding as of year-end 1999. P\&L and VaR data series are maintained by the banks to assess compliance with the Basle market risk capital requirements -- they serve as a gauge of the forecast accuracy of the models used for internal risk management. Regulations

\footnotetext{
${ }^{1}$ Jorion (2000) studies the usefulness of VaR disclosures in banks' annual and quarterly financial reports for forecasting risk.
} 
stipulate that estimates are to be calculated for a 99 percent lower critical value of aggregate trading P\&L with a one-day horizon. The forecasts provide a lower bound on aggregate trading P\&L that should be breached 1 day in 100 .

We evaluate the $\mathrm{VaR}$ forecasts in several ways. First, the null hypothesis of a 99 percent coverage rate is tested. Two important findings are that, unconditionally, the VaR estimates tend to be conservative relative to the $99^{\text {th }}$ percentile of $\mathrm{P} \& \mathrm{~L}$. However, at times losses can substantially exceed the VaR and such events tend to be clustered. This suggests that the banks' models, besides a tendency toward conservatism, have difficulty forecasting changes in the volatility of P\&L.

In part, the empirical performance of current models reflects difficulties in structural modeling when portfolios are large and complex. Large trading portfolios can have exposures to several thousand market risk factors, with individual positions numbering in the tens of thousands. It is virtually impossible for the models to turn out daily VaRs that measure the joint distribution of all material risks conditional on current information. The models therefore employ approximations to reduce computational burdens and overcome estimation hurdles. Additionally, we identify modeling practices and regulatory constraints that may affect the precision, particularly the conservativeness, of the VaR forecasts.

To further assess the performance of the banks' structural models, we compare their VaR forecasts with those from a standard GARCH model of the bank's P\&L volatility. The GARCH model is reduced form and attempts no accounting for changes in portfolio composition. In principal, the banks' structural models should deliver superior forecasts. Our results, however, indicate that the bank VaR models are not better than simple models of volatility. The GARCH model of P\&L generally provides for lower VaRs and is better at predicting changes in volatility. Because of the latter, the GARCH model permits comparable risk coverage with less regulatory capital.

Reduced form forecasts based on time-varying volatility offer a simple alternative to structural models that may warrant further consideration. While the GARCH P\&L model used here ignores current trading positions, such models can be adapted to account for changes in portfolio composition if such information is available. At a minimum, the results presented here illustrate that even naive reduced-form, time series models might serve as a useful ingredient in VaR forecasting. 
The remainder of the paper is organized as follows. Section I defines the data and describes the distribution of daily P\&L and bank VaRs. Section II presents the econometric methodology used to evaluate the performance of the models against the observed P\&L. Section III considers some current practices and difficulties in constructing structural models of large complex trading portfolios, which might help to explain the performance of the banks' VaR estimates. A final section provides some general conclusions.

\section{Daily Trading P\&L and VaR}

Daily profit and loss from trading activities and the associated VaR forecasts were collected from 6 large banking institutions subject to the Basle capital standards for trading risk. The trading revenue is based on position values recorded at the close of day and, unless reported otherwise, represents the bank holding company's consolidated trading activities. These activities include trading in interest rate, foreign exchange, and equity assets, liabilities, and derivatives contracts. Trading revenue includes gains and losses from daily marking to market of positions. Also included is fee income net of brokerage expenses related to the purchase and sale of trading instruments, excluding interest income and expenses.

The daily VaR estimates are maintained by the banks for the purpose of forecast evaluation or "back-testing" and are required by regulation to be calculated with the same risk model used for internal measurement of trading risk. The VaRs are for a one-day ahead horizon and a 99 percent confidence level for losses, i.e., the $1 \%$ lower tail of the P\&L distribution. Because the internal models are based on positions at the close of business preceding the forecast day, they omit intra-day position changes. The bank models also omit net fee income although it is included in reported trading P\&L.

Summary statistics are reported in Table 1 for daily P\&L and VaR data from January 1998 through March 2000. For these and other statistics reported below, each bank's daily P\&L and VaR are divided by the bank's full-sample standard deviation of P\&L to protect confidentiality. All banks reported positive average profits over the period. Sizeable differences in average $\mathrm{P} \& \mathrm{~L}$ and standard deviation across banks (not shown) correspond to differences in the size of trading activity, although column 2 of the Table also indicates significant disparity in mean P\&L relative to its variation. In column 4 , we report the $99^{\text {th }}$ percent losses of the P\&L distributions, the statistic forecasted by VaR. These losses, coming once in 100 days, are quite 
large and are clustered at about 3 standard deviations below the mean. As a result, the excess kurtosis estimates (relative to the Normal distribution) displayed in column 5 are also large.

The last three columns of Table 1 show summary statistics for the banks' $99^{\text {th }}$ percentile VaRs. For 5 of 6 banks, the average VaR lies outside the lower $99^{\text {th }}$ percentile P\&L, with VaRs for four banks ranging from 1.6 to over 3 times their respective $99^{\text {th }}$ percentile P\&Ls. At the $99^{\text {th }}$ percentile, P\&L would be expected to violate VaR 5 times in 500 trading days. However, only one bank experienced more than three violations. In this sense the VaR forecasts appear quite conservative, a finding that is given more attention in the analysis below.

While violations of $\mathrm{VaR}$ are infrequent, the magnitudes can be surprisingly large. For two banks the mean violation is more than two standard deviations beyond the VaR. For one bank, it is more than four standard deviations beyond the mean VaR. To get a sense of the size of these violations, consider a parametric such as the Normal as a benchmark. Under a Normal distribution the probability of a loss just one standard deviation beyond a $99 \% \mathrm{VaR}$ is $.04 \%$. The probability of a loss two standard deviations beyond $99 \%$ is virtually zero. For a Student-t distribution with 5 degrees of freedom, which is quite fat-tailed, the probability of a one standard deviation exceedence is only .3\% and of a two standard deviation, .1\%. In this sense, losses of the magnitude seen in our sample are quite far beyond the VaR.

Histograms of P\&L are presented in Figure 1 for the six banks. In all histograms, daily $\mathrm{P} \& \mathrm{~L}$ are de-meaned and divided by their standard deviation. At least 5 of the 6 banks exhibit extreme outliers, with a preponderance of the outliers in the left tail. Both the skewness estimates reported in Table 1 and the histograms in Figure 1 suggest that the portfolio returns tend to be left-skewed.

In Figure 2, we display the time series of each bank's P\&L and corresponding one-day ahead $99^{\text {th }}$ percentile VaR forecast (expressed in terms of the standard deviation of that bank's $P \& L)$. The plots tend to confirm the conservativeness of the VaR forecasts where violations of $\mathrm{VaR}$ are relatively few but large. The plots also show differences in VaR performances among banks. For banks 1, 2, and 6, VaRs are in the general vicinity of the lower range of their P\&Ls, but for banks 3, 4, and 5 this is not the case. The VaRs for these 3 banks also appear to exhibit trends. In particular, banks 4's VaR trends down while bank 5's VaR trends up.

The large losses in Figure 2 occurred during the turbulent period in world debt markets between August and October 1998, marked by the devaluation of the Russian Ruble, Russian 
debt default (August) and the near-collapse of a large U.S. hedge fund (September). Table 2 (column 1) shows that during this period, average returns are lower, standard deviations of the P\&L for most banks are exceptionally large, and the $99^{\text {th }}$ percentiles are blown out. As shown in column 3, almost all violations for the bank VaRs occurred in this period. Figure 3 shows the timing and magnitudes of the violations, again expressed in standard deviations.

Based on quarterly financial reports, the poor performance for most of the banks primarily reflects losses on interest rate positions, although some banks also reported losses in other trading activity (foreign exchange, equity and commodities). While counterparty defaults on derivative contracts spiked up in this period, the dollar magnitudes still made only a small contribution to trading losses. ${ }^{2}$

These findings suggest that P\&L may be correlated across banks, a potential concern to bank supervisors because it raises the specter of systemic risk - the simultaneous realization of large losses at several banks. In the upper panel of Table 3, cross-correlations between banks' daily P\&Ls are reported. While uniformly positive, the correlation coefficients for daily P\&L are generally low, mostly below .2. The daily correlations are low even for the subset of observations August-October 1998. Low correlations may reflect differences in portfolio compositions among banks. That is, even when market disruptions are widespread, shocks across different markets do not necessarily occur on the same calendar day. Additionally, trading firms have some discretion in the exact timing for reporting losses or gains in P\&L, especially for inactively traded instruments. When P\&L is aggregated over multi-day horizons, these idiosyncrasies may be less important. For example, over 5-day holding periods, the P\&L cross-correlations approximately double (not shown).

The lower panel of Table 3 displays correlations for daily VaR across banks. The VaR correlations are as often negative as they are positive and no clear pattern of co-movement is evident. Results are qualitatively the same even when the sample is restricted to the AugustOctober 1998 period and they are the same using 5-day average VaRs. These findings are

${ }^{2}$ We have no direct information on the banks' market-making activity in derivatives during this period, however, changes in notional positions in derivatives are sometimes used as an indicator of changes in the volume of derivatives activity. Based on quarter-end financial statements, the notional amounts of the derivatives positions for the banks studied here, as well as for bank dealers more generally, increased moderately in the last two quarters in 1998. Moreover, the notional amounts of the banks' OTC contracts, particularly interest rate contracts, also increased. 
consistent with different patterns in the bank VaRs displayed in Figure 2 and contrast with the small but positive daily cross-correlations in P\&L.

\section{Testing Model Performance}

In this section we study the forecast accuracy of the bank VaR estimates and their sensitivity to daily portfolio volatility. Denote the portfolio's P\&L by $r_{t}$, so that each day the bank forecasts $\mathrm{r}_{\mathrm{t}+1}$. The VaR forecast is the quantity $\overline{\mathrm{r}}_{\mathrm{t}+1}$ such that $\operatorname{pr}\left(\mathrm{r}_{\mathrm{t}+1}<\overline{\mathrm{r}}_{\mathrm{t}+1}\right)=\alpha$ over the next trading day. Here $\alpha=.01$, so that the model predicts a lower bound on losses not to be exceeded with $99 \%$ confidence.

\section{A. Forecast Evaluation}

The traditional approach to validating such interval forecasts is to compare the targeted violation rate, $\alpha$, to the observed violation rate. The first column of Table 4 reports the actual rates at which violations occurred for the 6 banks. The average violation rate across banks is less than $1 / 2$ of one percent. Column 2 reports likelihood ratio (LR) statistics for the null of a $1 \%$ violation rate. The p-values, shown in square brackets, are the probabilities of the likelihood ratio values exceeding the observed value under the $1 \%$ null.

These $\mathrm{p}$-values indicate that one of the coverage rates is significantly different from $1 \%$ at standard test levels. In addition, the LR test is undefined for one bank which had no violations. Both rejections arise because the frequency of violations is less than the desired one percent. Because of the small samples involved, unconditional coverage tests are known to have low power against alternative hypotheses (e.g., Kupiec (1995), Christoffersen (1998), Berkowitz (2001)).

More powerful tests are developed by Christoffersen (1998) who observes that not only should violations occur $1 \%$ of the time, but they should also be independent and identically distributed over time. Statistically, the variable defined as

$$
\begin{aligned}
I_{t} & =1 \text { if violation occurs } \\
& =0 \text { if no violation occurs }
\end{aligned}
$$

should be an iid Bernoulli sequence with parameter $\alpha$. Likelihood ratio tests of this null are easily constructed. These tests are referred to as conditional coverage and reported in column 3 
of Table 4, with p-values shown in square brackets. At conventional significance levels, the VaR forecasts are rejected for two banks. A third bank shows a p-value of .14.

A useful feature of the likelihood framework is the following identity:

$$
\mathrm{LR}_{\mathrm{cc}}=\mathrm{LR}_{\mathrm{uc}}+\mathrm{LR}_{\mathrm{ind}}
$$

That is, the conditional coverage test $\left(\mathrm{LR}_{\mathrm{cc}}\right)$ can be decomposed into a test of the unconditional coverage $\left(\mathrm{LR}_{\mathrm{uc}}\right)$, i.e., violation rate of $\alpha$, plus a test that violations are independent $\left(\mathrm{LR}_{\mathrm{ind}}\right)$.

Column 4 reports the results of LR tests for first-order serial dependence. ${ }^{3}$ The p-values suggest that for 2 banks, given a violation on one day there is a high probability of a violation the next day (higher than 1\%). Similarly, the last column in Table 4 reports the sample autocorrelation, $\operatorname{corr}\left(\mathrm{I}_{\mathrm{t}}, \mathrm{I}_{\mathrm{t}-1}\right)$, a diagnostic suggested by Christoffersen and Diebold (2000). Monte Carlo p-values indicate two significant first-order autocorrelations. While these results are limited to first-order serial dependence, as noted earlier, almost all of the VaR violations occurred during a single three-month period.

\section{B. Comparisons with a Benchmark Model}

The clustering of violations suggests that the volatility of P\&L may be time varying to a degree not captured by the models. To further pursue the potential for predictable volatility, we formulate an alternative VaR model determined from an $\operatorname{ARMA}(1,1)$ plus $\operatorname{GARCH}(1,1)$ model of portfolio returns. That is, we estimate the following reduced form model of $r_{t}$

$$
r_{t}=\mu+\rho r_{t-1}+u_{t}+\lambda u_{t-1}
$$

where $u_{t}$ is an iid innovation with mean zero and variance $\sigma_{t}$. The volatility process $\sigma_{t}$ is described by

$$
\sigma_{\mathrm{t}}=\omega+\theta \mathrm{u}_{\mathrm{t}-1}^{2}+\phi \sigma_{\mathrm{t}-1}
$$

3 The tests are restricted to first-order dependence, rather than considering higher-order dependence as well, because of the small number of observations. 
where $\omega, \theta$ and $\phi$ are parameters to be estimated. We apply the standard GARCH model where innovations are assumed to be conditionally Normal. Thus the $99 \%$ VaR forecast at time $\mathrm{t}$ is given by $\hat{r}_{t+1}-2.33 \hat{\sigma}_{t+1}$, where $\hat{r}_{t+1}$ is the predicted value of $r_{t+1}$ from equation (1) and $\hat{\sigma}_{t+1}$ is the estimated volatility from equation (2). ${ }^{4}$

A time-series model of $P \& L$ is a natural benchmark for evaluating the banks' VaR models, whose hallmark has been the employment of detailed information on current positions and their exposures to the various market risk factors. The reduced form model cannot account for changes in current positions or relationships between positions and the market risk factors because it is fit to the aggregate returns data. It cannot be used for sensitivity or scenario analysis. Nonetheless, it is potentially a more tractable approach for capturing trend and time varying volatility in a banks’ $\mathrm{P} \& \mathrm{~L}$ without the structure that makes large-scale models so complex and unwieldy.

It is worth pointing out that by fitting the time series model to reported P\&L, any systematic errors in the reported numbers are incorporated into the model. This would give the reduced-form model an advantage over the banks' models if the latter were not calibrated to reflect reported P\&L. For example, if banks' smooth daily P\&L, the reported numbers would have a tighter distribution than actual P\&L. For present purposes, we simply accept the reported daily numbers.

The ARMA and GARCH parameters are estimated each day with data available up to that point. To obtain stable estimates for the initial period, forecasts for days 1 through 165 are in-sample. Rolling out-of-sample forecasts begin after day 165, which is in the third week of August 1998 except for one bank (where it is May 1998). Out-of-sample estimates are updated daily. Given parameter estimates, we forecast the next day's $99 \%$ VaR assuming Normality of the GARCH innovations. The resultant forecasts, both within and out-of sample, are shown in Figure 4 by the solid line, along with the P\&L and the internal model forecasts. One-day ahead reduced-form forecasts appear to track the lower tails of P\&L remarkably well. Compared to the structural model, the time series model does far better at adjusting to changes in volatility.

\footnotetext{
${ }^{4}$ Note that it is possible for the reduced form ARMA+GARCH VaR to be positive. This would occur if the conditional mean of the distribution is large so that $\hat{r}_{t+1}>2.33 \hat{\sigma}_{t+1}$.
} 
Summary statistics and backtests for the GARCH model VaRs are presented in Table 5. The second column shows that the GARCH model successfully removes first-order persistence in banks' P\&L volatility (as well as higher-order persistence). The average GARCH VaRs shown in column 3 are also lower than average bank VaRs, except for bank 6, and the number of violations shown in column 4 average out to about 1 percent. Thus, on average, the GARCH VaRs achieve the targeted violation rate and a $99^{\text {th }}$ percentile VaR coverage. The mean violation rate for the GARCH VaRs also is lower than that of the banks' VaRs.

While this last result would be expected simply because the bank VaRs are more conservative, more conservative VaRs also should produce smaller aggregate violations and maximum violations. ${ }^{5}$ However, this is not the case. Aggregate violations (column 4 times column 5) and maximum violations (see below) for the GARCH VaRs are comparable to the bank model VaRs, even though the bank VaRs are more conservative. These results indicate a potentially important advantage for the reduced-form GARCH model. The magnitudes of the banks' VaR forecasts are used to determine regulatory capital requirements, and likely influence banks' internal capital allocations as well. The GARCH VaRs are able to deliver lower required capital levels without producing larger violations. As described below, this reflects the GARCH model VaRs greater responsiveness to changes in $\mathrm{P} \& \mathrm{~L}$ volatility.

Formal back-tests of the GARCH models are presented in the bottom panel of Table $5 .^{6}$ The backtest results provide little basis to distinguish between the GARCH and bank VaR modeling approaches. In terms of coverage, one GARCH VaR model is rejected at standard significance levels. Even though the GARCH VaRs on average have a 1 percent violation rate and the bank models less than a $1 / 2$ percent violation rate, the rejection rate is the same for both sets of models. Results for independence of violations also are similar between the two modeling approaches. For the GARCH VaRs two banks are rejected for independence in violations.

\footnotetext{
${ }^{5}$ Under either a normal distribution or heavy-tailed distributions, such as the t distribution, the conditional expected value of lower tail returns is increasing in the lower critical tail value, while the unconditional, aggregate, and maximum expected values are inversely related to the lower critical tail value.

${ }^{6}$ Backtests were also carried out only for the out-of-sample forecasts, which account for about 75 percent of the full sample results. For the out-of-sample period, the average bank VaR was about the same as for the full sample, while the average of mean violations was somewhat lower. The average violation rate also was very close to .01. Average bank results for the backtests (coverage, dependence, etc) were very similar to those for the full sample period.
} 
Despite the comparability of the backtests, the GARCH models' greater responsiveness to changes in P\&L volatility is illustrated for the August-October 1998 period when $\mathrm{P} \& \mathrm{~L}$ volatility rose substantially. Table 6 compares model performances during this 3-month period. Even though the GARCH model VaRs are smaller over the full sample, the bank and GARCH VaRs are comparable during this period. For this 3-month period, the GARCH VaRs increased from 80 to 250 percent over their average VaRs during the 3 months prior to August 1998 for 4 of the 5 banks with violations. The bank VaRs in comparison were 20 percent lower to 30 percent higher than their respective averages over the preceding 3 months. As a result, the performances of the bank and GARCH VaRs are comparable in terms of average, aggregate and maximum violations.

While these results show that the GARCH VaR forecasts compare favorably with the banks' VaRs, the GARCH model is not unassailable. A plot of the GARCH violations in Figure 5, along with the results presented in Table 5, indicate that some clustering remains. Also, while the average violation rate for the GARCH VaRs is 1 percent, other statistics such as kurtosis indicate heavy tails in the GARCH P\&L residuals. These results are due to the GARCH model's inability to adequately reflect the sharp increase in P\&L volatility in the latter part of 1998.

Some further evidence of this is provided by the GARCH model parameter estimates for different sample periods. For banks 1 through 4, GARCH and ARCH parameters jump as the sample period is extended to include the period of heightened P\&L volatility. The sum of the GARCH and ARCH parameters briefly reach one but subsequently decline below one as the sample is further extended. Excluding 1998 from the sample period, the sum of the GARCH and ARCH parameters remain below one for all banks. These results are suggestive of an environment subject to regime shifts, which cannot be captured by the standard GARCH model (see Gray (1996)). ${ }^{7}$

\section{Limitations of Bank VaR Models}

Our findings indicate that banks' $99^{\text {th }}$ percentile VaR forecasts tend to be conservative and, for some banks, are highly inaccurate. In terms of forecast accuracy and the size of

\footnotetext{
${ }^{7}$ We also estimated the VaR using an IGARCH model, where the sum of the ARCH and GARCH coefficients is constrained to equal one throughout the sample. Violations were again clustered in the August-October 1998 period.
} 
violations, the bank VaR forecasts could not out-perform forecasts based simply on an ARMA+GARCH model of the banks' daily P\&L. These results are at least partly indicative of difficulties in building large-scale structural VaR models. We also can identify some common modeling practices and regulatory constraints that lead to inaccurate forecasts.

The global trading portfolios of large trading banks contain tens of thousands of positions with several thousand market risk factors (interest rates, exchange rates, equity and commodity prices). Given the large number of positions and risk factors and the need to generate daily forecasts, it is impossible for the structural models to accurately measure the joint distribution of all material market risk factors, as well as the relationships between all risk factors and trading positions. To estimate the portfolio's risk structure, the banks make many approximations and parameters are often estimated only roughly. While this may appear to give representation to a wide range of potential risks, the various compromises reduce any forecasting advantage.

The forecast limitations of structural modeling extend to capturing time-varying volatility. None of the structural-based models makes any systematic attempt to capture time variation in the variances and covariances of market risks. As for evaluating exposures to liquidity or other market crises, banks are mostly limited to performing stress exercises on their portfolios. $^{8}$ By reducing the risk factor to a univariate time series, the reduced-form model used here offers a more tractable approach to estimating P\&L mean and volatility dynamics. While the reduced-form approach does not account for changes in portfolio composotion, this limitation can be relaxed by estimating GARCH effects for historically simulated portfolio returns to current positions, rather than historically observed returns. ${ }^{9}$

Regarding the conservative bias in bank VaRs, several bank model features along with regulatory constraints may provide potential explanations. As indicated above, all banks exclude net fee income from VaR forecasts. When compared to actual P\&L, this will give bank VaRs a

\footnotetext{
${ }^{8} \mathrm{We}$ are aware of one bank that extends its VaR horizon for positions that are sizable relative to the market, thereby allowing for a possible slow liquidation. For more on this approach to modeling liquidity risk see Berkowitz (2000).

${ }^{9}$ Barone-Adesi, Giannopoulos, and Vosper (1999) apply GARCH to historically simulated returns at the individual risk factor level under covariance parameter restrictions. Lopez and Walter (2000) report favorable results applying GARCH to portfolio returns as against applying GARCH at the risk factor level. Engle and Manganelli (1999) suggest reduced-form forecasting alternatives to GARCH. In particular, they advocate directly modeling the dynamics of the VaR rather than mean and variance dynamics. A reduced-form approach to VaR forecasting was originally suggested by Zangari (1997).
} 
conservative bias, since net fee income is believed to be a large part of average (positive) trading P\&L. The actual bias cannot be determined since banks do not separately report net fee income.

If we were to adjust reported P\&L downward by, say, subtracting one half of the bank's average $P \& L$ from its reported $P \& L$, we find that violation rates increase but that they are still conservative on average. Subtracting 100 percent of each bank's average P\&L from reported P\&L produces an average violation rate close to one percent.

In either case, these $P \& L$ adjustments would leave essentially unchanged the violation rates of the 3 banks with the most conservative VaRs. Moreover, this kind of level shift in the $\mathrm{P} \& \mathrm{~L}$ has the effect of worsening the clustering phenomenon. The less conservative VaR results in more violations in the tumultuous August-October 1998 period. We would argue that a better approach would be to include forecasts of net fee income in the VaRs. The reduced-form VaR forecasts used here extrapolate P\&L mean, as well as volatility, and thus implicitly include net fee income. ${ }^{10}$

A second practice that also may contribute to conservative bank VaRs is that VaRs may be estimated for subgroups of positions, such as for foreign exchange positions and interest rate positions. To obtain a VaR for the global portfolio, subgroup VaRs are simply summed. Since the sub-portfolio VaRs are each intended to be calibrated to a $99^{\text {th }}$ percentile, the summation will overstate global $99^{\text {th }}$ percentile $\mathrm{VaR}$ as it allows for no diversification or hedging affects among the sub-portfolios. Of the banks whose VaRs are among the most conservative, several make extensive use of the sub-portfolio addition procedure.

Certain regulatory standards may also contribute to the VaRs being both conservative and displaying limited response to changes in volatility. Regarding the latter, regulatory guidelines require that $\mathrm{VaR}$ estimates reflect market volatility over at least a one-year horizon, which precludes rapid adjustment to changes in current market volatility. Forecasts may be conservative in part because regulations require that banks whose global $\mathrm{VaR}$ is an aggregate of sub-portfolio VaRs must use the simple summation procedure. Further, the only formal regulatory test of bank VaRs is a one-sided "backtest" -- a bank is deemed to have failed the backtest if there are more than four violations of VaR over the past 250 days. This can lead to a

\footnotetext{
${ }^{10}$ Another omission that could introduce systematic bias in the VaRs is that VaR forecasts for day $t$, based on end-of day $t-1$ positions do not include intraday risk whose effects will be reflected in end-of-day P\&L.
} 
higher capital requirement and may provide an incentive for the bank to be conservative in its forecast.

To the extent that there are incentives for banks to be conservative, we expect them to be inversely related to management's confidence in its model. Indeed, we find that the VaRs of banks 3, 4 and 5 are a lot more conservative than those of banks 1,2 and 6. The former set of banks has have less modeling experience and generally have less sophisticated models than the latter banks.

\section{Conclusions}

This study has presented the first direct evidence on the performance of Value-at-Risk models for large trading firms. The results show that the VaR forecasts for six large commercial banks have exceeded nominal coverage levels over the past two years and, for some banks, VaRs were substantially removed from the lower range of trading P\&L. While such conservative estimates imply higher levels of capital coverage for trading risk, the reported VaRs are less useful as a measure of actual portfolio risk.

Despite the detailed information employed in the bank models, their VaR forecasts did not out-perform forecasts based simply on an ARMA plus GARCH model of the banks' P\&L. Compared to these reduced-form forecasts, the bank VaRs did not adequately reflect changes in $\mathrm{P} \& \mathrm{~L}$ volatility. These results may reflect substantial computational difficulties in constructing large-scale structural models of trading risks for large, complex portfolios. We also identify modeling practices and regulatory constraints that might harm VaR accuracy.

Reduced-form or "time-series" models of portfolio P\&L cannot account for positions' sensitivities to current risk factor shocks or changes in current positions. However, their parsimony and flexibility are convenient and accurate for modeling the mean and variance dynamics of P\&L. While the forecasts used here did not account for current positions, the reduced-form approach is amenable to this if used in conjunction with historical simulation methods. In a larger sense, the P\&L time series models are complementary to the large-scale models. The structural models are forward looking and they permit firms to examine the effects of individual positions on portfolio risk. Time series models may have advantages in forecasting and as a tool for identifying the shortcomings of the structural model. 
To a certain extent, our study is limited by the fact that banks only forecast a single percentile of the portfolio distribution. Significantly more could be learned about the empirical performance of internal valuation models if density forecasts were recorded. Density forecast evaluation techniques described in Diebold, Gunther and Tay (1998) and Berkowitz (2001) provide researchers with substantially more information to assess the dimensions in which models need improvement and those in which models do well. 


\section{References}

Barone-Adesi, G. K. Giannopoulos and L. Vosper (1999), "VaR without Correlations for Portfolios of Derivative Securities,"Journal of Futures Markets, 19, 583-602.

Basak, S. and Shapiro, A. (2000), "Value-at-Risk Based Risk Management: Optimal Policies and Asset Prices," forthcoming, Review of Financial Studies.

Basle Committee on Banking Supervision, Amendment to the Capital Accord to Incorporate Market Risks, January 1996.

Beder, T. S. (1995), "VAR: Seductive but Dangerous," Financial Analysts Journal, September, $12-24$.

Berkowitz, J. (2000), "Breaking the Silence," Risk, October, 105-108.

Berkowitz, J. (2001), “Testing the Accuracy of Density Forecasts," forthcoming, Journal of Business and Economic Statistics

Bollerslev, T. (1986), "Generalized Autoregressive Conditional Heteroskedasticity," Journal of Econometrics, 31, 307-327.

Christoffersen, P. (1998), "Evaluating Interval Forecasts," International Economic Review, 39, 841-862.

Christoffersen, P. and F. X. Diebold (2000), "How Relevant is Volatility Forecasting for Financial Risk Management," Review of Economics and Statistics, 82, 12-22.

Diebold, F. X., Gunther, T. A. and Tay, A. S. (1998), "Evaluating Density Forecasts," International Economic Review, 39, 863-883.

Dimson, E. and P. Marsh (1995), "Capital Requirements for Securities Firms," Journal of Finance, 50, 821-851.

Duffie, D. and J. Pan. (1997), “An Overview of Value at Risk”, Journal of Derivatives, Spring 1997, 4, 7-49.

Engle, R. F. and S. Manganelli (1999), "CAViaR: Conditional Autoregressive Value-atRisk by Regression Quantiles," manuscript, University of California, San Diego.

Figlewski, S. (1997), "Forecasting Volatility," Financial Markets, Institutions, and Instruments 6, Monograph series of the Stern School of Business, NYU.

Gray, S. (1996), "Modeling the conditional distribution of interest rates as a regime-switching process," Journal of Financial Economics, 42, 27-62. 
Hendricks, D. (1996), "Evaluation of Value-at-Risk Models Using Historical Data," Economic Policy Review, Federal Reserve Bank of New York, April, 39-69.

Jorion, P. (2000), "How Informative are Value-at-Risk Disclosures," manuscript, University of California, Irvine.

Jorion, P. (2001). Value-at-Risk: the New Benchmark for Controlling Market Risk. Chicago: McGraw-Hill.

JP Morgan (1996). RiskMetrics, Technical Document. $4^{\text {th }}$ Edition. New York.

Lopez, J. and Walter, C. (2000). "Evaluating Covariance Matrix Forecasts in a Value-atRisk Framework," manuscript, Federal Reserve Bank of San Francisco.

Kupiec, P. (1995). “Techniques for Verifying the Accuracy of Risk Measurement Models," Journal of Derivatives, 3, 73-84.

Marshall, C. and M. Siegel (1997), "Value-at-Risk: Implementing a Risk Measurement Standard," Journal of Derivatives, 1, 91-111.

Pritsker, M. (1997), "Evaluating Value at Risk Methodologies: Accuracy versus Computational Time," Journal of Financial Services Research, 12, 201-242.

Zangari, P., 1997. "Streamlining the Market Risk Measurement Process,” RiskMetrics Monitor, 1, 29-35. 
Table 1. Bank P\&L and VaR Summary Statistics

\begin{tabular}{|c|c|c|c|c|c|c|c|c|c|}
\hline & \multirow[b]{2}{*}{ Obs } & \multicolumn{5}{|c|}{ Daily P\&L } & \multicolumn{3}{|c|}{ Daily VaR } \\
\hline & & mean & $\begin{array}{l}\text { standard } \\
\text { deviation }\end{array}$ & $\begin{array}{l}99^{\text {th }} \\
\text { percentile }\end{array}$ & $\begin{array}{l}\text { excess } \\
\text { kurtosis }\end{array}$ & skew & $\begin{array}{l}\text { mean } \\
\text { VaR }\end{array}$ & $\begin{array}{l}\text { number } \\
\text { violations }\end{array}$ & $\begin{array}{l}\text { mean } \\
\text { violation }\end{array}$ \\
\hline Bank 1 & 569 & .964 & 1.00 & -1.78 & 11.63 & -.993 & -1.87 & 3 & -2.12 \\
\hline Bank 2 & 581 & .737 & 1.00 & -2.26 & 4.53 & .094 & -1.74 & 6 & -.741 \\
\hline Bank 3 & 585 & .375 & 1.00 & -2.73 & 23.87 & -3.13 & -4.41 & 3 & -3.18 \\
\hline Bank 4 & 573 & .595 & 1.00 & -1.59 & 2.31 & .860 & -5.22 & 0 & NA \\
\hline Bank 5 & ${ }^{\mathrm{a}} 746$ & .253 & 1.00 & -2.78 & 3.41 & -.617 & -5.62 & 1 & -.775 \\
\hline Bank 6 & 586 & .608 & 1.00 & -.967 & 142.1 & -8.25 & -1.72 & 3 & -5.84 \\
\hline
\end{tabular}

Notes: Daily profit and loss data reported by large commercial banks for January 1998 through March 2000. Each bank's data are divided by its sample standard deviation to protect the confidentiality of individual institutions. ${ }^{a}$ Data begins in May 1997. Mean violation refers to the loss in excess of the VaR. 
Table 2. Bank P\&L and VaR Summary Statistics

August to October 1998

\begin{tabular}{|c|c|c|c|c|c|c|c|c|c|}
\hline & \multirow[b]{2}{*}{ Obs } & \multicolumn{5}{|c|}{ Daily P\&L } & \multicolumn{3}{|c|}{ Daily VaR } \\
\hline & & mean & $\begin{array}{l}\text { standard } \\
\text { deviation }\end{array}$ & minimum & $\begin{array}{l}\text { excess } \\
\text { kurtosis }\end{array}$ & skew & $\begin{array}{l}\text { mean } \\
\text { VaR }\end{array}$ & $\begin{array}{l}\text { number } \\
\text { violations }\end{array}$ & $\begin{array}{l}\text { mean } \\
\text { violation }\end{array}$ \\
\hline Bank 1 & 63 & .175 & 1.76 & -7.01 & 4.58 & -1.32 & -2.32 & 3 & -2.12 \\
\hline Bank 2 & 64 & .076 & 1.89 & -4.26 & 1.46 & .787 & -2.28 & 5 & -.862 \\
\hline Bank 3 & 65 & -.907 & 1.84 & -8.68 & 7.65 & -2.53 & -4.63 & 3 & -3.18 \\
\hline Bank 4 & 63 & .045 & .773 & -1.89 & 0.99 & -.434 & -4.66 & 0 & NA \\
\hline Bank 5 & 65 & .064 & 1.60 & -5.51 & 1.99 & -.837 & -5.09 & 1 & -.775 \\
\hline Bank 6 & 65 & .171 & 2.28 & -14.2 & 41.1 & -5.92 & -1.42 & 2 & -7.99 \\
\hline
\end{tabular}

Notes: Daily profit and loss data as reported by large commercial banks in the wake of the Russian default crisis, August 1998 to October 1998. For further details on the data, see Table 1. 
Table 3. Correlations of Profit and Loss and VaR Across Individual Banks

A. P\&L Correlation Coefficients

\begin{tabular}{lcccccc}
\hline & Bank 1 & Bank 2 & Bank 3 & Bank 4 & Bank 5 & Bank 6 \\
\hline Bank 1 & 1.00 & & & & & \\
Bank 2 & .434 & 1.00 & & & & \\
& $(10.1)$ & & & & & \\
Bank 3 & .206 & .102 & 1.00 & & & \\
& $(4.81)$ & $(2.39)$ & & & & \\
Bank 4 & .164 & .085 & .358 & 1.00 & & \\
& $(3.84)$ & $(1.98)$ & $(8.36)$ & & & \\
Bank 5 & .053 & .171 & .117 & .122 & 1.00 & \\
& $(1.29)$ & $(3.99)$ & $(2.73)$ & $(2.84)$ & & \\
Bank 6 & .154 & .165 & .197 & .108 & .108 & 1.00 \\
& $(3.60)$ & $(3.85)$ & $(4.59)$ & $(2.52)$ & $(2.53)$ & \\
\hline
\end{tabular}

B. VaR Correlation Coefficients

\begin{tabular}{lcccccc}
\hline & Bank 1 & Bank 2 & Bank 3 & Bank 4 & Bank 5 & Bank 6 \\
\hline Bank 1 & 1.00 & & & & & \\
Bank 2 & -.033 & 1.00 & & & & \\
& $(-.777)$ & & & & & \\
Bank 3 & .122 & .207 & 1.00 & & & \\
& $(-2.84)$ & $(3.02)$ & & & & \\
Bank 4 & .064 & -.779 & -.202 & 1.00 & & \\
& $(1.48)$ & $(-5.72)$ & $(-4.72)$ & & & \\
Bank 5 & -.184 & .749 & .072 & -.742 & 1.00 & \\
& $(-4.30)$ & $(-8.59)$ & $(1.67)$ & $(-17.4)$ & & \\
Bank 6 & -.404 & -.229 & -.220 & .119 & .131 & 1.00 \\
& $(-9.45)$ & $(8.64)$ & $(-5.15)$ & $(2.78)$ & $(3.06)$ & \\
\hline
\end{tabular}

Notes: Correlation coefficients for bank profit and loss and value-at-risk calculated with a matched sample of 482 daily observations; t-statistics are shown in parentheses. 
Table 4. Backtests of Large-Scale VaR Models

\begin{tabular}{|c|c|c|c|c|c|}
\hline & Violation Rate & Coverage & $\begin{array}{l}\text { Conditional } \\
\text { Coverage }\end{array}$ & Independence & $\begin{array}{l}\text { Serial } \\
\text { Correlation }\end{array}$ \\
\hline Bank 1 & 0.005 & $\begin{array}{l}1.54 \\
{[.214]}\end{array}$ & $\begin{array}{l}1.57 \\
{[.455]}\end{array}$ & $\begin{array}{l}.0321 \\
{[.858]}\end{array}$ & $\begin{array}{l}-.00533 \\
{[.885]}\end{array}$ \\
\hline Bank 2 & 0.010 & $\begin{array}{l}.00693 \\
{[.934]}\end{array}$ & $\begin{array}{l}4.01 \\
{[.135]}\end{array}$ & $\begin{array}{l}4.00 * \\
{[.046]}\end{array}$ & $\begin{array}{l}.158 * \\
{[.016]}\end{array}$ \\
\hline Bank 3 & 0.005 & $\begin{array}{l}1.70 \\
{[.193]}\end{array}$ & $\begin{array}{l}8.81 * \\
{[.012]}\end{array}$ & $\begin{array}{l}7.11 * * \\
{[.008]}\end{array}$ & $\begin{array}{l}.330 * * \\
{[.001]}\end{array}$ \\
\hline Bank 4 & 0.000 & NA & NA & NA & NA \\
\hline Bank 5 & 0.001 & $\begin{array}{l}8.92 * * \\
{[.003]}\end{array}$ & $\begin{array}{l}8.93^{*} \\
{[.012]}\end{array}$ & $\begin{array}{l}.00271 \\
{[.959]}\end{array}$ & $\begin{array}{l}-.00137 \\
{[.995]}\end{array}$ \\
\hline Bank 6 & 0.005 & $\begin{array}{l}1.71 \\
{[.191]}\end{array}$ & $\begin{array}{l}1.74 \\
{[.419]}\end{array}$ & $\begin{array}{l}.0312 \\
{[.860]}\end{array}$ & $\begin{array}{l}-.00511 \\
{[.885]}\end{array}$ \\
\hline
\end{tabular}

Notes: Alternative backtests of large-scale VaR models in operation at six commercial banks. Data are daily and span from January 1998 to March 2000. NA indicates the bank had no violations in the sample period. P-values are displayed in square brackets. * and ** denote significance at the 1 and 5 percent levels, respectively. 
Table 5. Backtests of Time-Series Model

$\operatorname{ARMA}(1,1)+\operatorname{GARCH}(1,1)$

\section{Summary Statistics}

\begin{tabular}{lcrrcc} 
& Obs & $\begin{array}{r}\text { Box-Ljung } \\
\text { Stat }\end{array}$ & $\begin{array}{r}\text { Mean } \\
\text { VaR }\end{array}$ & $\begin{array}{c}\text { Number } \\
\text { Violations }\end{array}$ & $\begin{array}{c}\text { Mean } \\
\text { Violation }\end{array}$ \\
\hline Bank 1 & 569 & .284 & -1.21 & 6 & -.829 \\
Bank 2 & 581 & .106 & -1.42 & 6 & -.362 \\
Bank 3 & 585 & 1.11 & -1.41 & 13 & -1.12 \\
Bank 4 & 573 & .356 & -1.35 & 4 & -.315 \\
Bank 5 & 746 & 2.89 & -2.10 & 12 & -.772 \\
Bank 6 & 586 & .005 & -2.40 & 2 & -7.21
\end{tabular}

\section{Backtests}

\begin{tabular}{|c|c|c|c|c|c|}
\hline & $\begin{array}{l}\text { Violation } \\
\text { Rate }\end{array}$ & Coverage & $\begin{array}{l}\text { Conditional } \\
\text { Coverage }\end{array}$ & Independence & $\begin{array}{l}\text { Serial } \\
\text { Correlation }\end{array}$ \\
\hline \multirow[t]{2}{*}{ Bank 1} & 0.011 & 0.018 & 3.97 & $3.96^{*}$ & $0.158 *$ \\
\hline & & [.894] & [.137] & {$[.047]$} & {$[.016]$} \\
\hline \multirow[t]{2}{*}{ Bank 2} & 0.010 & 0.069 & 0.132 & 0.125 & -0.010 \\
\hline & & [.934] & [.936] & {$[.723]$} & {$[.436]$} \\
\hline \multirow[t]{2}{*}{ Bank 3} & 0.022 & $6.57 * *$ & $11.4 * *$ & $4.79 *$ & $0.134 *$ \\
\hline & & {$[.010]$} & {$[.003]$} & {$[.029]$} & {$[.025]$} \\
\hline \multirow[t]{2}{*}{ Bank 4} & 0.007 & 0.584 & 0.640 & 0.056 & -0.007 \\
\hline & & {$[.445]$} & {$[.726]$} & {$[.812]$} & {$[.756]$} \\
\hline \multirow[t]{2}{*}{ Bank 5} & 0.016 & 2.37 & 4.16 & 1.787 & $0.068 *$ \\
\hline & & {$[.124]$} & {$[.125]$} & [.181] & {$[.050]$} \\
\hline \multirow[t]{2}{*}{ Bank 6} & 0.003 & 3.43 & 3.45 & 0.014 & -0.003 \\
\hline & & {$[.064]$} & {$[.179]$} & {$[.907]$} & [.964] \\
\hline
\end{tabular}

Notes: Alternative backtests of large-scale VaR models in operation at six qualifying commercial banks. P-values are displayed in square brackets. Box-Ljung statistics are for first-order serial correlation in the squares of the standardized GARCH residuals. The 5\% critical value is 3.84 , the $10 \%$ value is 2.71 . * and ** denote significance at the 1 and 5 percent levels, respectively. 
Table 6. Bank and GARCH Model Comparisons August to October 1998

\begin{tabular}{|c|c|c|c|c|c|c|c|c|c|}
\hline & \multirow[b]{2}{*}{ obs } & \multicolumn{4}{|c|}{ Bank VaRs } & \multicolumn{4}{|c|}{ GARCH VaRs } \\
\hline & & $\begin{array}{c}\text { mean } \\
\text { VaR }\end{array}$ & $\begin{array}{c}\text { number } \\
\text { viol }\end{array}$ & $\begin{array}{c}\text { mean } \\
\text { viol }\end{array}$ & $\begin{array}{l}\max \\
\text { viol }\end{array}$ & $\begin{array}{c}\text { mean } \\
\text { VaR }\end{array}$ & $\begin{array}{c}\text { number } \\
\text { viol }\end{array}$ & $\begin{array}{c}\text { mean } \\
\text { viol }\end{array}$ & $\begin{array}{l}\max \\
\text { viol }\end{array}$ \\
\hline Bank 1 & 63 & -2.32 & 3 & -2.12 & -4.70 & -2.90 & 5 & -.981 & -4.33 \\
\hline Bank 2 & 64 & -2.28 & 5 & -.862 & -2.46 & -3.41 & 3 & -.410 & -.748 \\
\hline Bank 3 & 65 & -4.62 & 3 & -3.18 & -4.13 & -3.12 & 7 & -1.45 & -4.08 \\
\hline Bank 4 & 63 & -4.66 & 0 & NA & NA & -1.71 & 0 & NA & NA \\
\hline Bank 5 & 65 & -5.08 & 1 & -.775 & -3.29 & -2.97 & 4 & -1.35 & -2.87 \\
\hline Bank 6 & 65 & -1.42 & 2 & -7.99 & -25.32 & -2.93 & 1 & -13.4 & -13.4 \\
\hline
\end{tabular}

Notes: Table compares value-at-risk forecasts as reported by large commercial banks during the period of August 1998 to October 1998 to forecasts from a reduced form model. The GARCH $\mathrm{VaR}$ forecast is based on an $\operatorname{ARMA}(1,1)$ with $\operatorname{GARCH}(1,1)$ with conditionally Normal innovations. For further details see Table 1. 
Figure 1. Bank Daily Profit/Loss Distributions
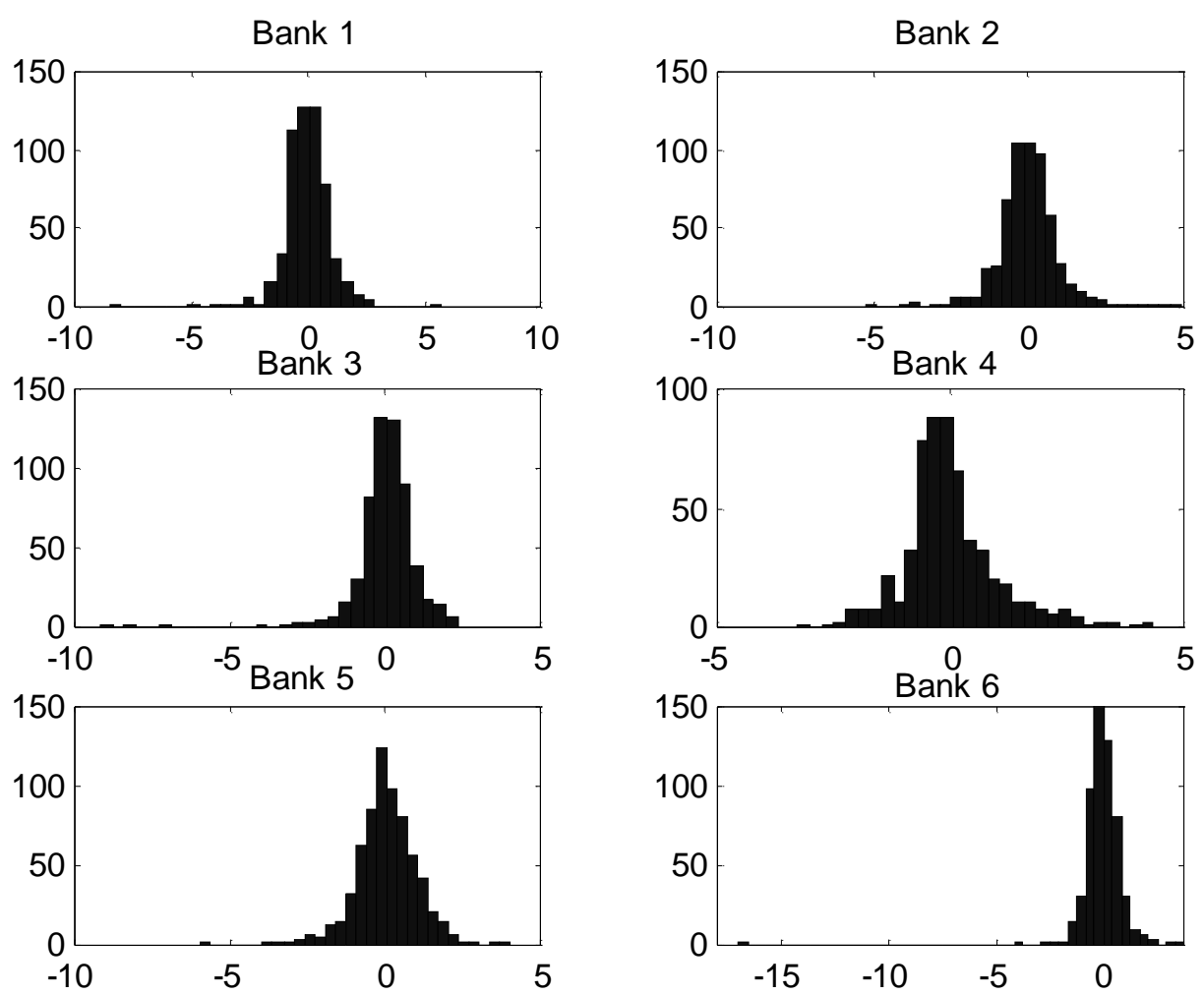

Notes: Histograms of daily profit and loss data reported by large commercial banks for January 1998 through March 2000. Data are de-meaned and expressed in standard deviations. See text for details. 
Figure 2. Bank Daily VaR Models
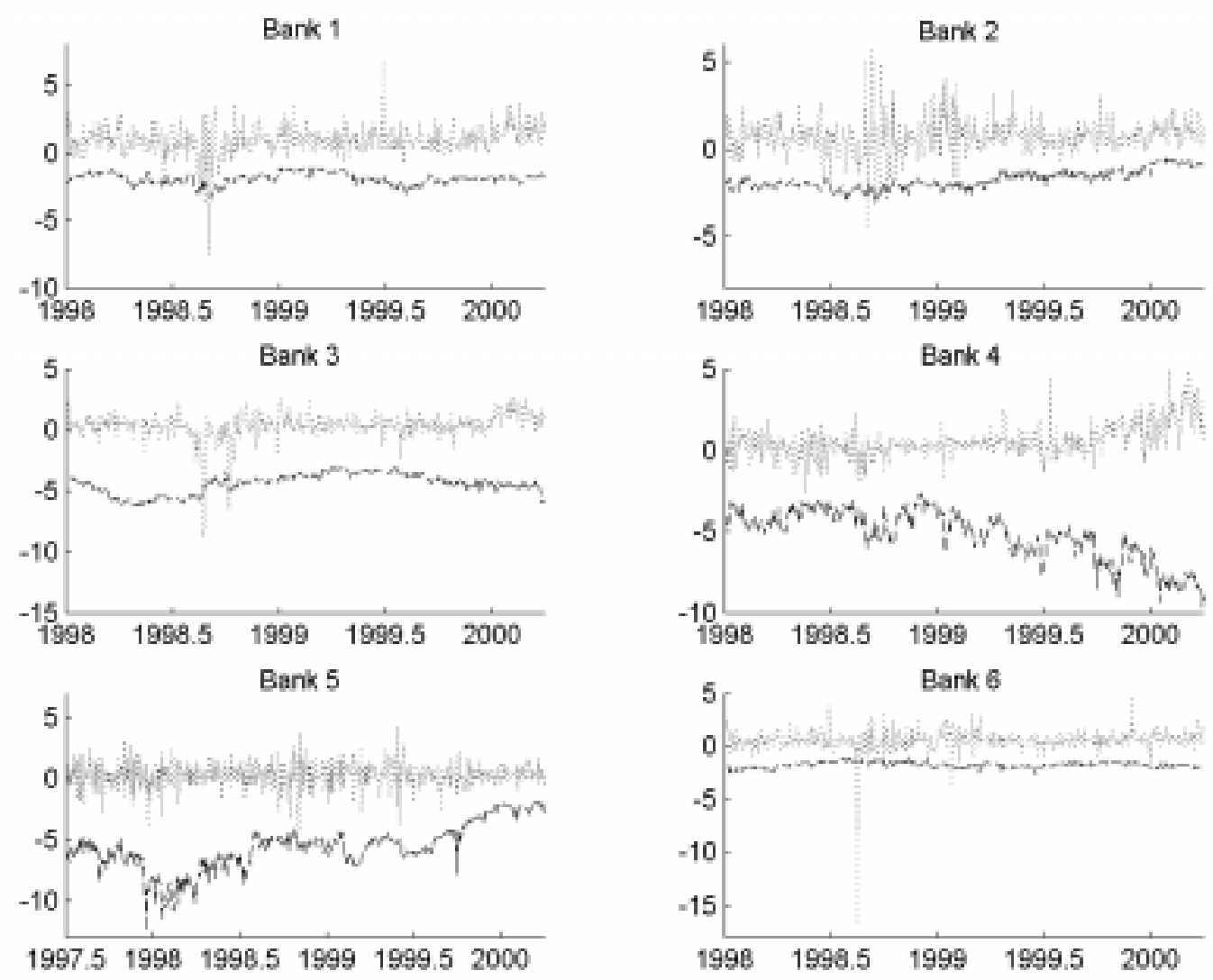

Notes: Time series of daily profit and loss data as reported by selected commercial banks for January 1998 through March 2000 (dotted lines) plotted with forecasts from an internal VaR model (dashed line). The model is used to forecast the 1-day ahead $99^{\text {th }}$ percentile of P\&L. 
Figure 3. Violations of Banks' 99\% VaR
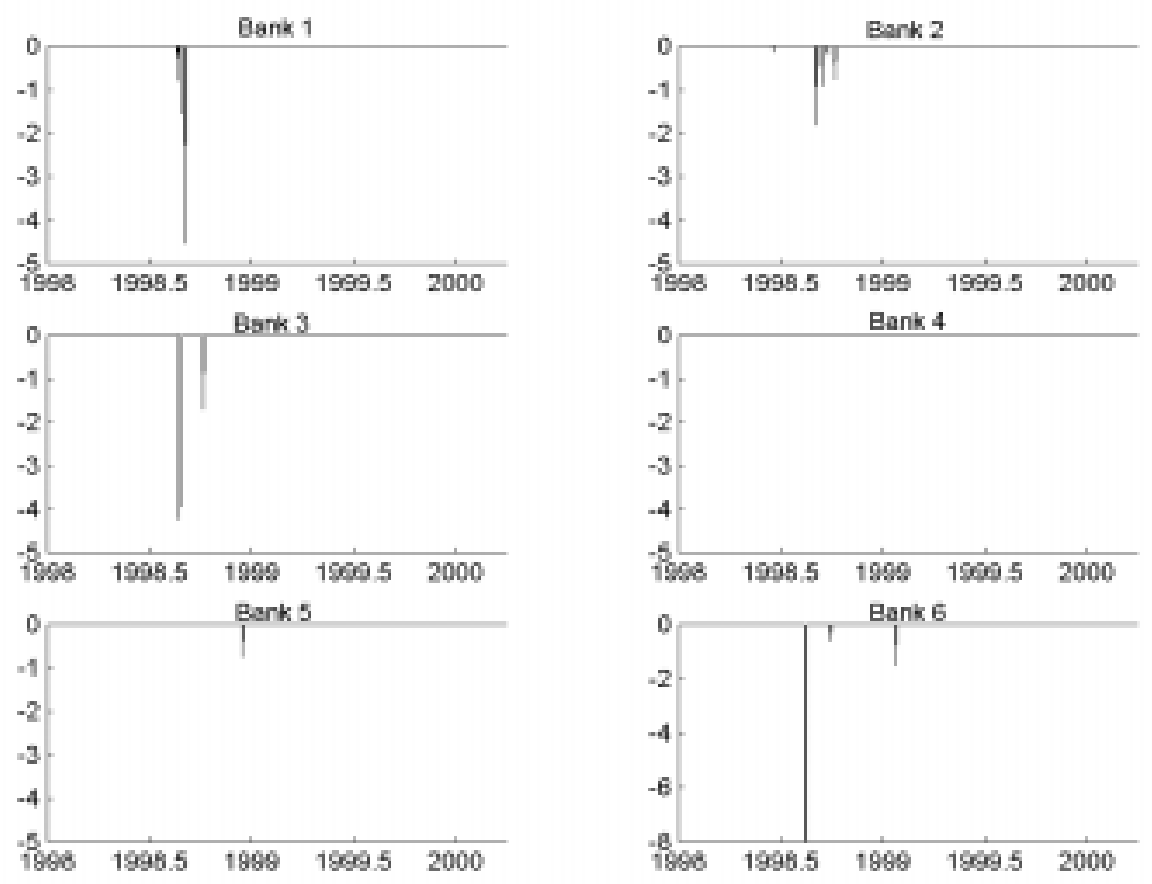

Notes: Plots show the daily P\&L for those days on which P\&L drops below the forecasted $99^{\text {th }}$ percentile given the internal bank models. Data are expressed in standard deviations. 
Figure 4. Daily Profit and Loss and a Simple Dynamic Model
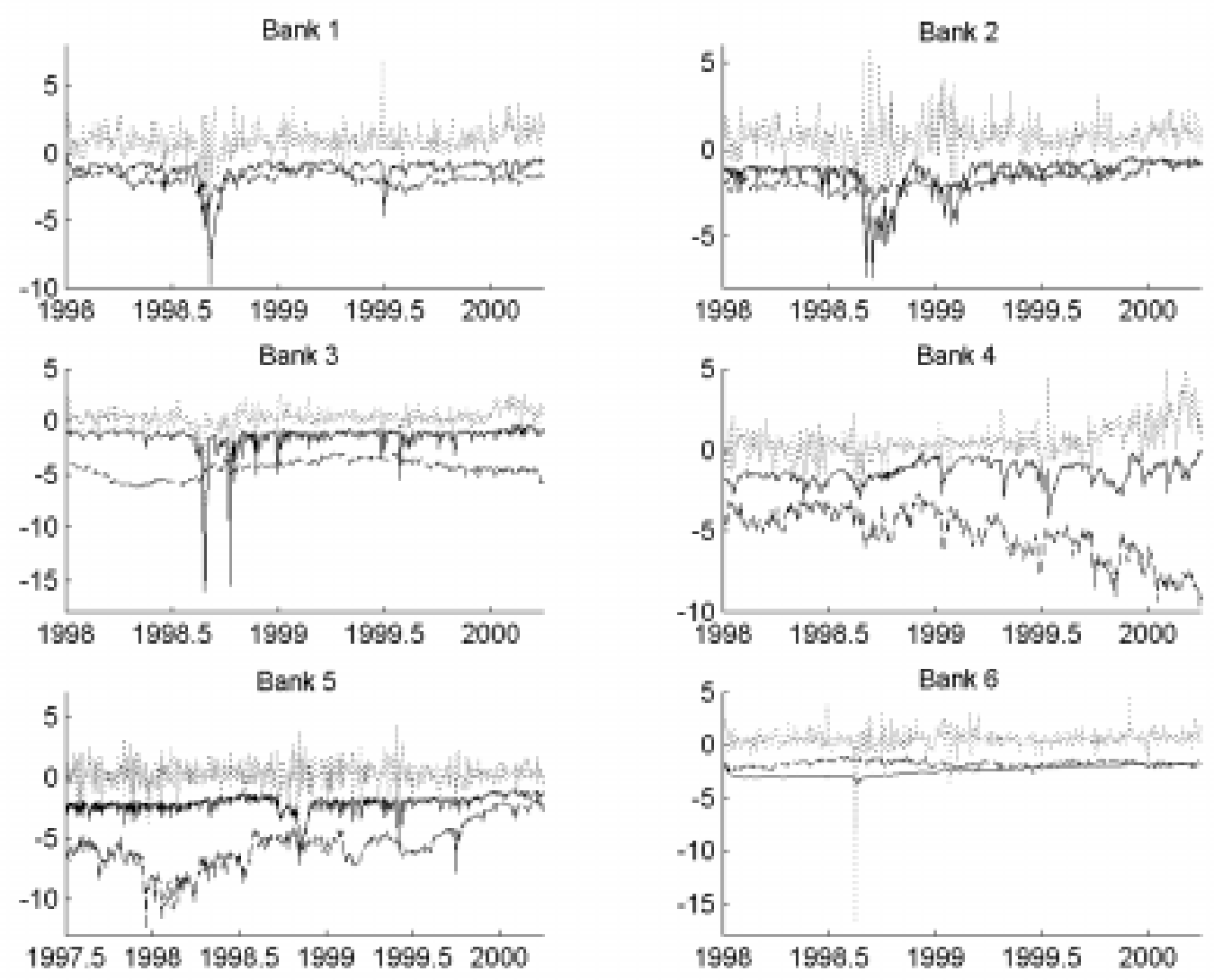

\section{--- Bank VaR \\ $\operatorname{ARMA}(1,1)+\mathrm{GARCH}(1,1)$}

Notes: Time series of daily profit and loss data as reported by selected commercial banks for January 1998 through March 2000 (dotted lines) plotted with two model forecasts. The two models are an internal VaR model (dashed line) and a reduced form ARMA $(1,1)$ with GARCH(1,1) Gaussian innovations. Both models are used to forecast the 1-day ahead $99^{\text {th }}$ percentile of P\&L. 
Figure 5. Violations of the 99\% GARCH-based VaR
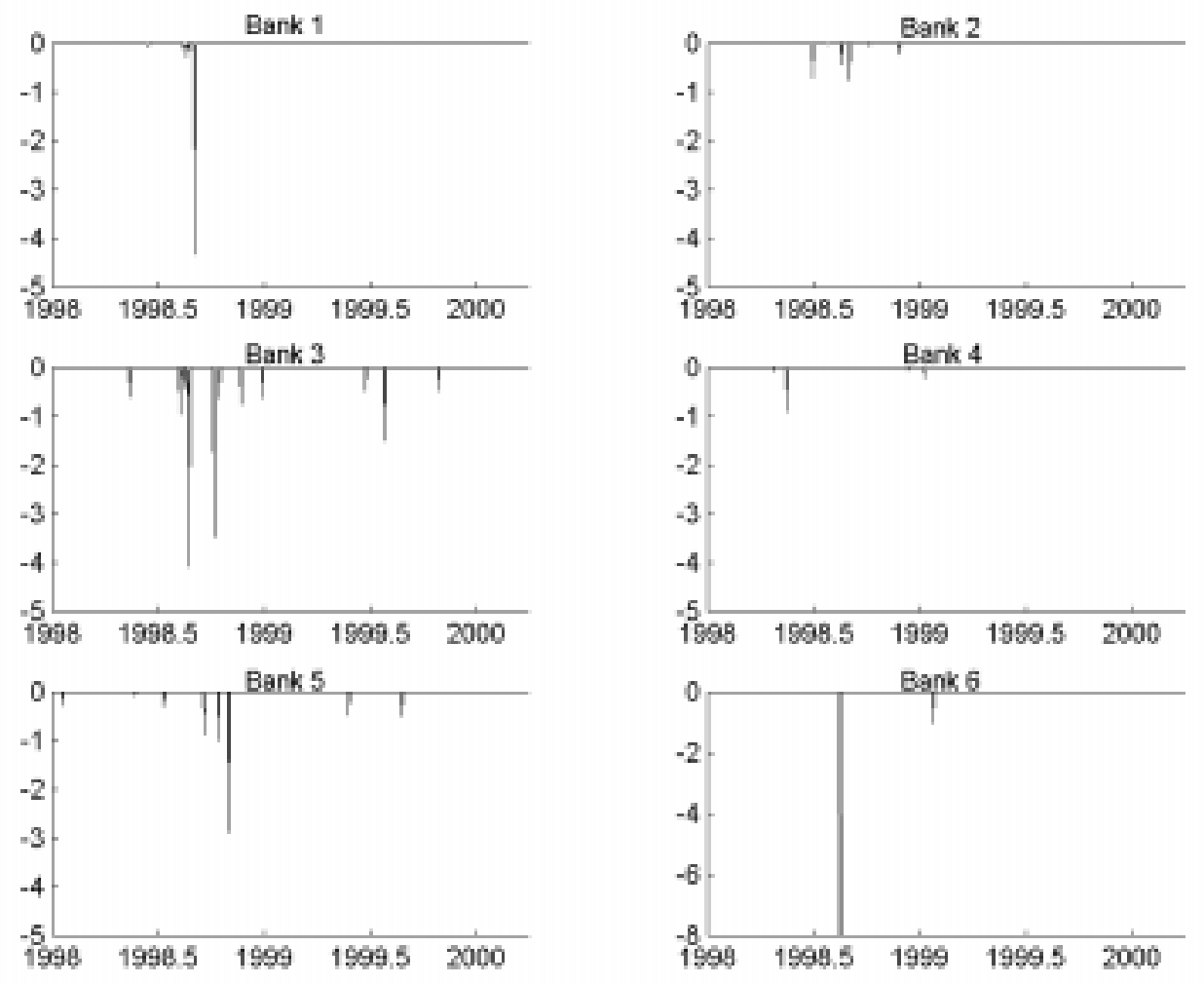

Notes: Plots show the daily P\&L for those days on which P\&L drops below the forecasted $99^{\text {th }}$ percentile given the internal bank models. Data are expressed in standard deviations. 